\title{
Quantification of lens opacification with a commercially available lensometer
}

\author{
S J Tuft, F W Fitzke, J Lawrenson, J Silver, J Marshall
}

\begin{abstract}
A clinical trial was undertaken to determine whether a commercially available lens opacity meter (LM701), which measures backward scattered light from the lens, provides reliable clinical information about the effect of lens opacities on visual acuity. At the 0.001 level of probability we found a significant relationship between the lens opacity meter reading and both the Snellen acuity and patient's age. For a given individual there was also a relationship between the difference in the lens opacity readings between eyes and the difference in the Snellen acuities. We could not demonstrate a relation between the lens opacity reading and either the refractive error, pupil size, or near visual acuity at this level of significance.
\end{abstract}

There is an increase in both the absorption and the scattering of light by the human lens during aging. For a given light exposure age related changes in the lens will cause a variation in both the total irradiance and the spectral distribution of the irradiance of the retina. Transmission losses are particularly significant at wavelengths shorter than $450 \mathrm{~nm} .{ }^{\prime}$ These changes are not solely the result of an increased thickness of the lens or a reduction in pupil diameter, ${ }^{2}$ but are in part due to aggregation and postsynthetic changes in the lens proteins, which produce local differences in the index of refraction. These changes produce scattering of light which is manifest subjectively as increased glare and objectively as reduced visual acuity.

Deciding on the contribution of lens opacities toward visual acuity loss can be a clinica challenge, such that a technique to quantify lens opacity would be of value in the assessment of patients with cataract. Some of the clinical effects of lens opacity may be gauged from an assessment of the visual acuity, while a simple and objective assessment of lens opacity can be gained by retroillumination or by slit-lamp examination. A number of techniques have been developed in an attempt to quantify lens opacity. These include photography of the lens by retroillumination ${ }^{4}$ and densitometric pattern analysis of the photographic negative ${ }^{5-7}$; resolution test target projection ophthalmoscopy ${ }^{8}$; the measurement of light back scattering from defined regions of the lens ${ }^{910}$; microdensitometry of photographic negatives of the lens obtained by using the Scheimpflug principle ${ }^{11}{ }^{12}$; the measurement of lens fluorescence spectra ${ }^{13}$; the grading of opacity by comparison with standards at slitlamp examination ${ }^{314}$; the comparison of retinal sensitivity loss at different wavelengths ${ }^{15}$; and the measurement of the contrast transfer ratio. ${ }^{16}$

None of these methods have been adapted to provide a source of quick and reliable information for the clinician.

Recently a commercially available device termed a lensometer has become available. This instrument, the lens opacity meter 701 (Interzeag Gmbh., Switzerland), utilises a beam of light $1.5 \mathrm{~mm}$ in diameter at $700 \mathrm{~nm}$ to produce back scatter from opacities on the optic axis of the lens. The back scattered light from the lens is then detected at a fixed angle of $27^{\circ}$ with respect to the incident beam, converted into an electric impulse, and recorded on an arbitrary scale between 0 and $100 .{ }^{17} \mathrm{~A}$ previous investigation using this instrument on a population with normal visual acuity reported an increase in lens opacity values with age, with a range from 4 to 25 units. ${ }^{18} 19$ Data from 13 patients with a variety of types of lens opacities showed that detection was best for diffuse opacity of the lens and that higher values were obtained following mydriasis. ${ }^{18}$

To determine if this instrument has a role in the clinical assessment of patients with lens opacities we present the results of 102 patients in whom cataract was suspected as the sole cause of a reduction in visual acuity, and in whom we correlated the refraction and visual acuity with the lensometer reading.

\section{Materials and methods}

Patients were selected from a population attending the refraction clinic at Moorfields Eye Hospital. For each patient a record was made of their subjective refraction, and their best corrected vision was measured with a standard Snellen chart under normal clinical conditions, which was then expressed as their decimal acuity. The design and handling of the LM701 is similar to that of a photographic slit-lamp, with the patient's chin placed on a rest and the instrument aligned and operated with a joy stick. A more complete description of the instrumentation is contained elsewhere. ${ }^{17}$ Observations were made in reduced illumination without dilatation of the pupil. For each eye the pupil diameter was recorded, and five consecutive readings were made with the patient fixating the instrument target, or with the instrument aligned with the centre of the pupil when this was prevented by poor acuity. The five readings were processed by an inbuilt minicomputer and the mean and the standard deviation derived. Left and right eyes were analysed separately except for difference analysis. The criterion that was adopted for statistical significance was $\mathrm{p}=0.001$.

Patients with a visual acuity of less than $6 / 6$ had a full ophthalmic examination, including funduscopy with dilatation, and the identification of a posterior segment abnormality that could account for their loss of visual acuity was the only
Correspondence to: S J Tuft.

Accepted for publication 23 August 1989 
criterion for exclusion from the study. Eyes in which a posterior chamber intraocular lens had been implanted with an intact posterior lens capsule were included, but four aphakic eyes were excluded from the statistical analysis.

The data were assessed by both linear and nonlinear regression analysis, and, although a slightly better fit was obtained with the latter, for the sake of clarity only linear regression is shown.

\section{Results}

Two hundred and two eyes of 102 patients (44 males and 58 females, age range 19 to 92 years, mean 65.9 years, $S D=16 \cdot 2$ ) were examined for this study. Two patients were uniocular. There were 57 patients (60 eyes) who had had an intraocular lens implant, and 11 eyes in which analysis was not possible because of incomplete data. $86 \%$ of the patients were over the age of 50 years. The mean patient age for the right eyes was 63.6 years (62 patients, $S D=16 \cdot 25$ years), and the mean pupil diameter was $4 \cdot 16 \mathrm{~mm}(\mathrm{SD}=$ $1 \cdot 22 \mathrm{~mm})$. The mean patient age for the left eyes was $62 \cdot 1$ years ( 58 patients, $S D=17 \cdot 42$ years), and the mean pupil diameter $4 \cdot 17 \mathrm{~mm}(\mathrm{SD}=1 \cdot 27$ $\mathrm{mm}$ ). A two tailed $t$ test comparing these groups was not significant (age, $\mathrm{p}=0.603$; pupil diameter, $\mathrm{p}=0.9$ ).

As expected, there was a significant reduction in the pupil diameter of the unoperated eyes with increasing age; the regression for right eyes had a slope of -0.0434 and an intercept of $6.923(r=$ $-0.5795, \mathrm{df}=60, \mathrm{p}<0.0001)$, while the left eyes had a slope of $-0 \cdot 0484$ and an intercept of $7 \cdot 175$ $(\mathrm{r}=-0.6619, \mathrm{df}=56, \mathrm{p}<0.0001)$. Despite obtaining readings in reduced illumination, 43 of $127(33.8 \%)$ of pupil diameters were less than 4 $\mathrm{mm}$; however, the diameters of all pupils were greater than the diameter of the LM701 beam.

Although values for lens opacity of up to 100 were possible, no patient in this study had a value greater than 56, despite an acuity of less than $6 / 60$ in some patients. For phakic eyes 71 of 125 $(56.8 \%)$ of the lensometer readings were greater than 20 , and there was a rapid increase in readings over the age of 60 years. The results of

TABLE I Results of linear regression analysis

\begin{tabular}{|c|c|c|c|c|c|c|}
\hline $\begin{array}{l}\text { LOM reading } \\
\text { versus: }\end{array}$ & & Slope & Intercept & $r$ & $d f$ & $p$ \\
\hline Age & $\begin{array}{l}\mathrm{R} \\
\mathrm{L}\end{array}$ & $\begin{array}{l}0.3866 \\
0.3442\end{array}$ & $\begin{array}{r}-0.4820 \\
0.6931\end{array}$ & $\begin{array}{l}0.6234 \\
0.5722\end{array}$ & $\begin{array}{l}62 \\
61\end{array}$ & $\begin{array}{l}0.0000 \\
0.0000\end{array}$ \\
\hline Pupil size & $\begin{array}{l}\mathbf{R} \\
\mathbf{L}\end{array}$ & $\begin{array}{l}-1 \cdot 5584 \\
-2 \cdot 1880\end{array}$ & $\begin{array}{l}29 \cdot 114 \\
31 \cdot 472\end{array}$ & $\begin{array}{l}-0.1747 \\
-0.2613\end{array}$ & $\begin{array}{l}64 \\
61\end{array}$ & $\begin{array}{l}0.1607 \\
0.0386\end{array}$ \\
\hline $\begin{array}{l}\text { Visual } \\
\text { acuity }\end{array}$ & $\begin{array}{l}\mathbf{R} \\
\mathbf{L}\end{array}$ & $\begin{array}{l}-15 \cdot 953 \\
-12 \cdot 708\end{array}$ & $\begin{array}{l}34 \cdot 041 \\
30 \cdot 934\end{array}$ & $\begin{array}{l}-0.5816 \\
-0.5179\end{array}$ & $\begin{array}{l}65 \\
63\end{array}$ & $\begin{array}{l}0.0000 \\
0.0000\end{array}$ \\
\hline $\begin{array}{l}\text { Visual } \\
\text { acuity (IOL) }\end{array}$ & $\begin{array}{l}\mathrm{R} \\
\mathbf{L}\end{array}$ & $\begin{array}{l}1.230 \\
0.626\end{array}$ & $\begin{array}{r}10 \cdot 010 \\
9 \cdot 395\end{array}$ & $\begin{array}{l}0.0395 \\
0.0497\end{array}$ & $\begin{array}{l}30 \\
28\end{array}$ & $\begin{array}{l}0.8300 \\
0.7943\end{array}$ \\
\hline $\begin{array}{l}\text { Near } \\
\text { acuity }\end{array}$ & $\begin{array}{l}\mathbf{R} \\
\mathbf{L}\end{array}$ & $\begin{array}{l}-14 \cdot 814 \\
-11 \cdot 303\end{array}$ & $\begin{array}{l}35 \cdot 277 \\
31 \cdot 801\end{array}$ & $\begin{array}{l}-0.3718 \\
-0.3326\end{array}$ & $\begin{array}{l}64 \\
61\end{array}$ & $\begin{array}{l}0.0021 \\
0.0077\end{array}$ \\
\hline $\begin{array}{l}\text { Spherical } \\
\text { equivalent }\end{array}$ & $\begin{array}{l}\mathbf{R} \\
\mathbf{L}\end{array}$ & $\begin{array}{l}-0.8534 \\
-0.5468\end{array}$ & $\begin{array}{l}21 \cdot 467 \\
20 \cdot 83\end{array}$ & $\begin{array}{l}-0.3674 \\
-0.2139\end{array}$ & $\begin{array}{l}60 \\
59\end{array}$ & $\begin{array}{l}0.0033 \\
0.0979\end{array}$ \\
\hline $\begin{array}{l}\text { Cylindrical } \\
\text { error }\end{array}$ & $\begin{array}{l}\mathbf{R} \\
\mathbf{L}\end{array}$ & $\begin{array}{l}-0.0141 \\
-0.0284\end{array}$ & $\begin{array}{l}-0.661 \\
-0.337\end{array}$ & $\begin{array}{l}-0.1564 \\
-0.3198\end{array}$ & $\begin{array}{l}60 \\
59\end{array}$ & $\begin{array}{l}0.2246 \\
0.0120\end{array}$ \\
\hline $\begin{array}{l}\text { Acuity (phakic) } \\
\text { difference (IOL) }\end{array}$ & & $\begin{array}{l}-13 \cdot 732 \\
-21 \cdot 010\end{array}$ & $\begin{array}{l}1 \cdot 0513 \\
1 \cdot 1080\end{array}$ & $\begin{array}{l}-0.6464 \\
-0.4586\end{array}$ & $\begin{array}{l}32 \\
38\end{array}$ & $\begin{array}{l}0.0000 \\
0.0029\end{array}$ \\
\hline
\end{tabular}

LOM=lensometer. $\mathrm{IOL}=$ intraocular lens. linear regression analysis of all of the data are shown in Table 1 , and it may be seen that there is a highly significant relationship between the lensometer readings and age, visual acuity, and visual acuity difference between pairs of phakic eyes. The changes in lensometer readings as a function of age for phakic patients are illustrated in Figure 1.

Figure 2 shows a plot of the lensometer reading versus the distance visual acuity for phakic eyes plotted as the decimal acuity. In both the right and left eyes there was a significant increase in the lensometer reading with a decrease in the visual acuity. Pseudophakic eyes were separately analysed and there was no significant correlation between the lensometer reading and the visual acuity (Table 1 ).

In a comparison between the lensometer reading and refractive error for phakic eyes, 64 of 119 eyes included $(53 \cdot 8 \%)$ were myopic. There was no significant relationship between the refractive error of these eyes and lensometer reading at the $\mathrm{p}=0.001$ level (Table 1 ). Similarly, there was no relationship between lensometer reading and refractive error when either sphere or cylinder were analysed separately.

To permit a comparison between the two eyes of each patient, we compared the difference between the lensometer readings for the right and left eyes with the difference between the visual acuities. The result again indicated that a reduction in visual acuity correlated with an increase in the lensometer reading at the level of significance of $\mathrm{p}<0.0001$. When eyes containing intraocular lenses were similarly analysed, the significance was less marked ( $p>0.001$ ) (Table 1). The relationship between the near visual acuity and the lensometer reading approached but did not attain significance at the $p=0.001$ level.

\section{Discussion}

The development of cataract is associated with a loss of visual acuity that is a function of both the increased absorption and scatter of light by the lens. Using the lens opacity meter LM701 we found a statistically significant correlation between the LOM reading and both age and visual acuity in phakic eyes. There was also a significant correlation between the difference in the $L O M$ reading and the difference in visual acuity between eyes. In contrast, there was no correlation between the LOM reading and the near visual acuity or refraction, or with pupil size despite a reduction of pupil size with increasing age.

An age related increase in the scatter of light by the lens has been previously noted. ${ }^{10} 19$ Using light back scatter from defined regions of the lens, Ben-Sira et $a l^{10}$ noted a continuous increase in opacity values for the anterior cortex from the age of 20 years in patients with visual acuity maintained at $6 / 6$, whereas opacity values for the nucleus did not begin to increase until after 50 years of age. In contrast, using microdensitometric analysis of Scheimpflug photographs, Hockwin $e a^{12}{ }^{12}$ recorded a continuous increase in the light scattered from the nucleus throughout life. An increase in the fluorescence from the 
Figure 1: A scatter plot of the lensometer reading (instrument units) versus age in years for phakic patients.

The regression lines for the right and left eyes and drawn separately. Note that there is a rapid increase in the higher lensometer values with age, and that the origin is very close to a zero lensometer reading.
Figure 2: A scatter plot of the lensometer reading as a function of the decimal visual acuity. Although in the population there is a wide spread of lensometer readings at each visual acuity level, the regression indicates that there is a significant negative correlation, such that an increased lensometer value corresponds to a reduced visual acuity.

\section{Lensometer Reading Versus Age}

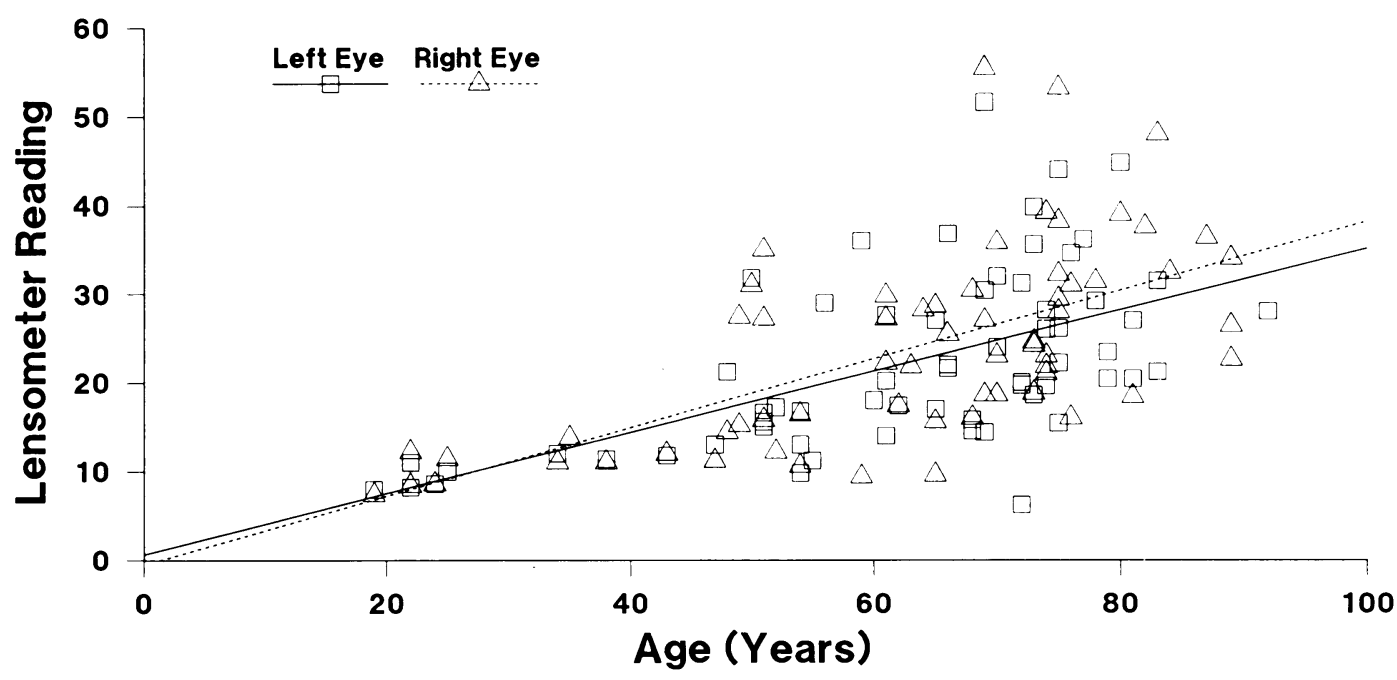

deeper layers of the cortex has also been observed after the age of 30 years.' From these data it follows that the eye can tolerate an increased colouration of the lens with some loss of overall and spectral transmission, and an increase in back scatter, without loss of visual acuity.

A number of different techniques have been used to calibrate the light that is back scattered from the lens. For example Goldmann' and BenSira $e t a l^{10}$ used part of the illuminating beam from a standard slit-lamp as a reference source, while Wolf and Gardiner ${ }^{20}$ used a stabilised light source to provide a photometric assay. Using the instrument under study De Natale $e t a l^{19}$ found that there was a relationship between age and opacity up to the age of 65 years. This correlates with the continuous increase of nuclear opacity with age demonstrated by a Scheimpflug camera. ${ }^{12}$ We confirmed an increase in the LOM reading with age. However, unlike the study by De Natale $e t a l^{19}$ we have included patients with pathological lens opacities in addition to those with aging changes. This is reflected in the

higher values for LOM readings of up to 56 instrument units in our study as opposed to 30 in their patients.

It may be assumed that there is a relation between the light that is back scattered from the lens and that which is forward scattered to the retina, but the form of this relation is not known and may depend on the nature and distribution of the light scattering elements in the lens. However, there is not a clear relationship between light scattered by the lens and disability as measured by visual acuity. ${ }^{21}$ Although some taxonomic studies emphasise the morphological features of lens opacity, ${ }^{14}$ we have not attempted to correlate the LOM reading with the type of lens opacity. It should be noted that Wegener and Hockwin ${ }^{18}$ studied 13 cataractous patients with a LM701 and noted an increase in the LOM value of approximately 4 units following mydriasis; they also considered that the instrument provided better evaluation of homogeneous rather than localised lens opacities.

In conclusion, we found the instrument to be

\section{Lensometer Reading Versus Visual Acuity}

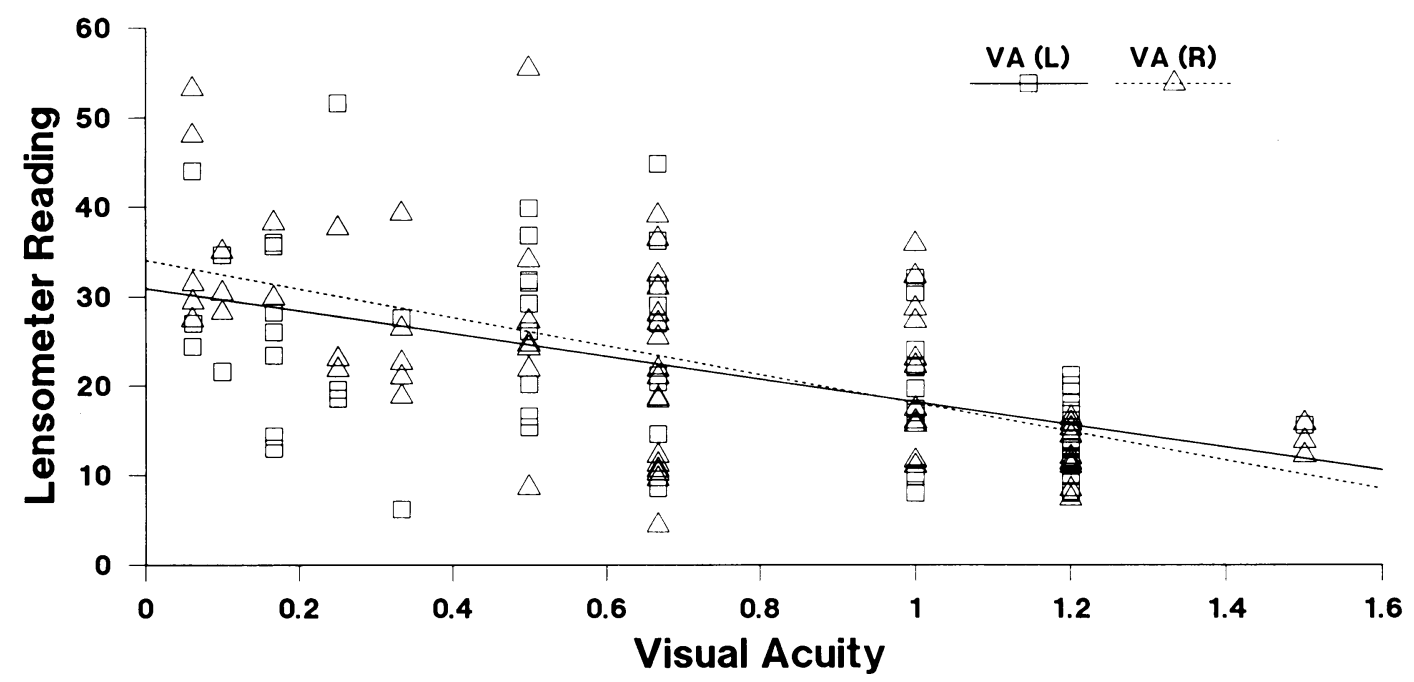


of little help in the estimation of the contribution made by lens opacity to visual loss on an individual basis, but after linear regression the LOM meter provided useful information on the contribution of lens opacities to visual acuity loss in a population with cataract. An instrument of this design may thus be of value in population studies to record the natural history of lens opacity, the ocular side effects of drug therapy, and the therapeutic effect of anticataract drugs. ${ }^{3}$ There was a wide variation in the value for lens scatter within a given age group and a wide spread of $\mathrm{LOM}$ values for the other variables examined. This variability may be the result of loss of retinal sensitivity and optic nerve function with aging, absorption by the lens, or morphological differences between lens opacities.

The authors have no proprietary interest in the LM701 lensometer. The Lens Opacity Meter 701 was kindly loaned by IntraOptics (UK) Ltd. We thank Peter Clark and Chris Jubb for help with the statistical analysis.

1 Lerman S, Borkman R. Spectroscopic evaluation and classification of the normal, aging, and cataractous lens. Ophthalmic Res 1976; 8: 335-53.

2 Weale RA. Notes on the photometric significance of the human crystalline lens. Vision Res 1961; 1: 183-91.

3 Brown NAP, Bron AJ, Sparrow JM. Methods for evaluation of lens changes. Int Ophthalmol 1988; 12: 229-35.

4 Fincham EF. Photographic recording of opacities of the ocular media. Br f Ophthalmol 1955; 39: 85-9.

5 Hockwin O, Weigelin E, Hendrickson P, Koch HR. Kontrolle des Trubungsverlaufs bei der Cataracta senilis durch Linsenphotographie im regredienten Licht. Klin Monatsbl Augenheilkd 1975; 166: 498-503.
6 Kawara T, Obazawa H. A new method for retroillumination photography of cataractous lens opacities. Am $\mathcal{F}$ Ophthalmol 1980; 90: 186-9.

7 Maclean $\mathrm{H}$, Taylor CJ. An objective staging for cortical cataract in vivo aided by pattern-analysing computer. Exp Eye Res 1981; 33: 597-602.

8 Cotlier E, Fagadau W, Cicchetti DV. Methods for evaluation of medical therapy of senile and diabetic cataracts. Trans Ophthalmol Soc UK 1982; 102: 416-22.

9 Goldmann H. Senile changes of the lens and vitreous. Am $\mathcal{J}$ Ophthalmol 1964; 57: 1-13.

10 Ben-Sira I, Weinberger D, Bodenheimer J, Yassur Y. Clinical method for measurement of light backscattering from the in method for measurement of light backscattering from the in

11 Brown N. Quantitative slit-lamp photography of the lens. Trans Ophthalmol Soc UK 1972; 62: 303-17.

12 Hockwin $\mathrm{O}$, Lerman S, Ohrloff $\mathrm{C}$. Investigations on lens transparency and its disturbances by microdensitometric analyses of Scheimpflug photographs. Curr Eye Res 1984; 3: $15-22$.

13 Strobel J, Jacobi KW, Lohmann W, Schmehl W. Die Bedeutung von Fluoreszenzspektren für die Beurteilung von Linsentrubungen. Klin Monatsbl Augenheilkd 1986; 189: $141-3$.

14 Sparrow JM, Bron AJ, Brown NAP, Ayliffe W, Hill AR. The Oxford clinical cataract classification and grading system. Int Ophthalmol 1986; 9:207-25.

15 Sample PA, Esterson FD, Weinreb RN, Boynton RM. The aging lens: in vivo assessment of light absorption in 84 human eyes. Invest Ophthalmol Vis Sci 1988; 29: 1306-11.

16 Hendrickson P, Robert Y. Contrast transfer ratio in normal, cataractous and intraocular implant lenses. A clinical photocataractous and intraocular implant lenses. A clinical photopapillometric study.

17 Flammer J, Bebie H. Lens opacity meter: a new instrument to quantify lens opacity. Ophthalmologica 1987; 195: 69-72.

18 Wegener A, Hockwin O. First experience with the Interzeag lens opacity meter in measuring normal and cataractous lens. Lens research 1988; 5: 183-90.

19 De Natale R, Flammer J, Zulauf M, Bebie T. Influence of age on the transparency of the lens in normals: a population study with help of the lens opacity meter 701 . Ophthalmologica $1988 ; 197 ; 14-8$.

20 Wolf E, Gardiner JS. Studies on the scatter of light in the dioptric media of the eye as a basis of visual glare. Arch Ophthalmol 1965; 74: 338-45.

21 Van Den Berg TJTP. Importance of pathological intraocular light scatter for visual disability. Doc Ophthalmol 1986; 61: 327-33. 